\title{
EXPERIÊNCIAS E EXPERIMENTAÇÕES AUDIOVISUAIS NO GSHOW, INSTAGRAM, YOUTUBE E GLOBOPLAY
}

\author{
José Jullian Gomes de Souza ${ }^{1}$
}

\begin{abstract}
Resumo
Este estudo investiga as experiências audiovisuais que estão sendo produzidas na e para a internet, durante a pandemia ocasionada pelo novo coronavírus. Para o estudo foram selecionadas as webséries: Se Eu Estivesse Aí (Gshow), Alta Sociedade, Baixa (Instagram), Sala de Roteiro (YouTube) e Diário de um Confinado (Globoplay) visualizadas como novas experimentações em áudio e vídeo, em diálogo com as orientações de restrição do contato presencial e isolamento social. Desta forma, objetiva-se analisar como deu-se a construção desses novos formatos, suas características e os desafios da produção dessas webséries no atual momento, bem como o uso das ferramentas e plataformas digitais de produção e distribuição on-line. Os procedimentos metodológicos adotados são de cunho qualitativo, estratégia de pesquisa descritiva e estudo de caso, destacando essas novas experiências e compreendendo o surgimento dessas webséries. $\mathrm{O}$ estudo revela que essas experimentações perpassam tanto pelos produtores independentes, quanto grandes grupos midiáticos. E apresenta uma nova possibilidade de produção e formato audiovisual, especificamente para o ambiente digital, podendo ser difundido em diálogo com as ferramentas digitais das plataformas on-line e redes sociais digitais.
\end{abstract}

Palavras-chave: Experiências audiovisuais. Websérie. Plataforma digital.

\section{AUDIOVISUAL EXPERIENCES AND EXPERIENCES ON GSHOW, INSTAGRAM, YOUTUBE AND GLOBOPLAY}

\begin{abstract}
This study investigates the audiovisual experiences that being produced on and for the internet, during the pandemic caused by the new coronavirus. For the study, the webseries were selected: Se Eu Estivesse Aí (Gshow), Alta Sociedade, Baixa (Instagram), Script Room (YouTube) and Diary of a Confined (Globoplay) viewed as new audio and video experiments, in dialogue with guidelines for restricting face-to-face contact and social isolation. Thus, the objective is to analyze how the construction of these new formats took place, their characteristics and the challenges of producing these web series at the current moment, as well as the use of digital tools and platforms for online production and distribution. The methodological procedures adopted are of a qualitative nature, descriptive research strategy and case study, highlighting these new experiences and understanding the emergence of these webseries. The study reveals that these experiments run through both independent producers and large media groups. And it presents a new possibility of production and audiovisual format, specifically for the digital environment and can be broadcast in dialogue with the digital tools of the online platforms and digital social networks.
\end{abstract}

Keywords: Audiovisual experiences. Webseries. Digital platform.

\footnotetext{
${ }^{1}$ Universidade Federal do Ceará (UFC). Mestre em Biblioteconomia pela Universidade Federal do Cariri (UFCA). Jornalista pela Universidade Federal do Ceará (UFC- Campus Cariri). Especialista em Língua Portuguesa e Literatura pelo Centro Univisertário de Juazeiro do Norte (Unijuazeiro). ORCID $<$ http://orcid.org/0000-0002-4007-8545>. E-mail: jullianjose64@gmail.com
} 


\section{Linguagens - Revista de Letras, Artes e Comunicação - ISSN 1981- 9943 \\ Blumenau, v. 14, n. 2, p. 181-195, maio/ago. 2020. \\ DOI: http://dx.doi.org/10.7867/1981-9943.2020v14n2p181-195}

\section{INTRODUÇÃO}

As experiências e experimentações da produção audiovisual na e para a internet, em decorrência das mudanças e transformações advindas e provocadas pela pandemia do novo coronavírus, é o tema central deste estudo. O olhar se volta para um tipo de produção audiovisual particular deste meio: as webséries ficcionais elaboradas para e nas plataformas digitais. $\mathrm{O}$ intuito é descortinar as movimentações em torno dessas atuais produções, seus formatos e estruturas de produção e distribuição, considerando como uma oportunidade de identificar as inferências que estão sendo realizadas para a continuidade da produção audiovisual em diálogo com as ferramentas e plataformas digitais no contexto atual.

Essa conjuntura permite a reflexão dessas experiências em áudio e vídeo, que não são inovadoras - no sentido de inéditas - deste atual cenário. Porém, são potencializadas e reorganizadas dentro de um ecossistema em detrimento das medidas sanitárias, do isolamento social e da quarentena da covid-19 que foi iniciada no primeiro semestre do ano de 2020 . Além disso, as webséries em análise inferem a reflexão sobre a introdução de novos elementos estéticos e de produção. Neste sentido, sendo o universo do entretenimento e do audiovisual um dos mais atingidos pela pandemia, toda uma programação audiovisual, sobretudo no âmbito da TV, ficou estagnada - principalmente entre os meses de março a julho de 2020 (período mais acentuado na pandemia). Por outro lado, a paralisação das atividades a exemplo de programas de auditórios, telenovelas, reality shows, séries e seriados, acarretou numa movimentação e reordenação para uma intensa usabilidade das mídias digitais. $\mathrm{O}$ que ocasionou no vislumbramento dessas produções audiovisuais no ambiente on-line.

É nesta paisagem midiática na qual estão inseridas as webséries que produtores, escritores e artistas têm se valido para experimentar e propor ambiências narrativas e formatos audiovisuais seriados que dialogam com os recursos e ferramentas contemporâneos. Neste sentido, Souza (2020) averigua que é dado ao ambiente digital um protagonismo e no qual ele realiza a função de mediador com o produto e o público, ou seja, entre as webséries, as plataformas digitais e os espectadores/usuários.

Assim, essa busca por novas formas de interação e conexão com o público foram e, a novidade torna-se uma marca constante da nova geração, utilizando as ferramentas disponíveis e uma imersão no universo tecnológico (BARCELLOS, 2017). Neste contexto, o objetivo principal é analisar esses novos formatos, suas características e os desafios da produção dessas webséries no atual momento ocasionada pela pandemia do novo coronavírus 
- identificadas como novas possibilidades, modelos de negócios e estratégias de produção que pode ou não serem difundidas após a pandemia e o fim do isolamento social.

Adota-se como estratégia metodológica a abordagem qualitativa, a pesquisa descritiva e o estudo de caso pautado em quatro webséries situadas em diferentes plataformas: $\mathrm{Se} \mathrm{Eu}$ Estivesse Aí (Gshow), Alta Sociedade, Baixa (Instagram), Sala de Roteiro (YouTube) e Diário de um Confinado (Globoplay). Desse modo, buscou-se definir algumas categorias para fazer a análise: a) estrutura das plataformas; b) recursos e ferramentas (seja para a produção ou distribuição do conteúdo); c) estrutura do conteúdo, a partir do funcionamento de cada uma das plataformas selecionadas para produzir a websérie; d) duração temporal de episódios e por temporada; e) cenários; f) dispositivos de captação das imagens e; g) modos de distribuição.

Em consonância com essa categorização, partiu-se para o uso da Análise de Conteúdo (AC) (BARDIN, 2016). A utilização da AC, ocorreu a partir da sua operacionalização enquanto método e utilização das seguintes etapas: organização da análise, codificação, categorização e inferência. Sendo assim, possível elaborar todo um percurso de análise não apenas visando o seu conteúdo, mas também a sua estrutura.

\section{A NARRATIVA SERIADA E O FENÔMENO DAS WEBSÉRIES}

A televisão surge no Brasil em 18 de setembro de 1950 e desde então o homem passou a acompanhar ao longo desses 70 anos de produção audiovisual diversas transformações, modificações e a expansão dos formatos, plataformas e produtos. Dentre essas transformações e surgimentos estão as narrativas seriadas e as séries de TV, que fazem com que cada sujeito passe a dedicar horas e mais horas semanais no acompanhamento dessas histórias serializadas. Inicialmente através do aparelho televisivo, mas com o processo de convergência e transmidiação a experiência televisiva é reconfigurada pelos processos comunicacionais na e com internet. Deste modo, é possível explicitar que há a construção de uma cultura das séries (SILVA, 2014, grifo nosso), no qual o autor destaca três condições para essa cultura e que dialogam com a proposição desta pesquisa: (1) a sofisticação das formas narrativas, (2) o contexto tecnológico que permite uma ampla circulação digital (on-line ou não) e (3) os novos modos de consumo, participação e crítica textual.

Mas, antes de ser incorporada às narrativas audiovisuais, a narrativa seriada tem sua origem nos folhetins jornalísticos datados do século XIX. De acordo com Zanetti (2009), ela foi apropriada pelo cinema e pela televisão, posteriormente adentrando o território das novas mídias. Dentre as características da narrativa seriada está a divisão em breaks (blocos), nos 


\section{Linguagens - Revista de Letras, Artes e Comunicação - ISSN 1981- 9943 \\ Blumenau, v. 14, n. 2, p. 181-195, maio/ago. 2020. \\ DOI: http://dx.doi.org/10.7867/1981-9943.2020v14n2p181-195}

quais o conteúdo do produto é intercalado com as propagandas e comerciais na linguagem televisiva. No Brasil, a televisão ainda ocupa uma figura central de destaque, com $77 \%$ da população acompanhando a programação durante sete dias por semana, como aponta a Pesquisa Brasileira de Mídia no ano de 2016.

Entende-se, assim, que o processo narrativo e serializado está na vida do homem como algo intrínseco a ele, pois "a narrativa está presente em todos os tempos, em todos os lugares, em todas as sociedades; a narrativa começa com a própria história da humanidade; não há, em parte alguma, povo algum sem narrativa" (BARTHES, 1971, p. 19). Ou seja, a narrativa funciona como uma estrutura, uma condicionante atrelada à sociedade e mantém um forte vínculo com a sua cultura, hábitos e modos de produção e consumo.

Para Machado (2000), a apresentação da serialização de forma descontínua e fragmentada funciona como uma estratégia das empresas, pois faz com que os telespectadores passem mais tempo sintonizados na TV para acompanhar a programação - ao menos num determinado programa até o final da sua exibição diária. Construindo, de tal modo, uma relação de proximidade entre o objeto televisão, o conteúdo audiovisual e a presença da audiência no outro lado da telinha.

Essa serialização da narrativa com o decorrer do tempo, das novas possibilidades industriais, culturais e tecnológicas adentra o território das mídias digitais, no qual é possível inferir a visualização de algumas transformações em sua estrutura de produção e experiência (seja para o produtor, seja para o espectador). Neste sentido, Silva e Santos (2015) explicam que a narrativa tem a capacidade de reconfigurar o olhar do fruidor e a compreensão do que foi experimentado. Assim, direcionando o olhar para o surgimento das webséries no universo digital, convergente, transmidiático e multiplataforma.

Conforme Hergesel, Pichiguelli e Silva (2019) as webséries têm registro do início dos anos 2000, a partir da ideia de hiperseriado como destaca Weller (2000), que já apontava para a proximidade entre o audiovisual e as novas mídias. Na literatura científica sobre o tema, dos anos 2000 até o tempo presente, diversos autores exploraram essa relação entre narrativa audiovisual e internet, estabelecendo condições e proposições para refletir sobre a sua constituição e definição, ainda que nunca em definitivo - o que possibilita a abertura para o eterno diálogo do desconhecido, de um novo olhar e um ângulo a ser explorado. Para não se deter sobre uma discussão conceitual, uma vez que não é o objetivo deste artigo, ancora-se na seguinte compreensão:

[...] a principal característica da websérie é que ela é pensada, criada e desenvolvida para a internet, com finalidade para reprodução em aparatos de tecnologia 


\title{
Linguagens - Revista de Letras, Artes e Comunicação - ISSN 1981- 9943 \\ Blumenau, v. 14, n. 2, p. 181-195, maio/ago. 2020. \\ DOI: http://dx.doi.org/10.7867/1981-9943.2020v14n2p181-195
}

emergente, como computadores, tablets, celulares e, mais recentemente, relógios digitais - ainda que tais produtos possam ser, posteriormente, veiculados em outras plataformas midiáticas, como televisores e projetores de vídeo (HERGESEL; PICHIGUELLI; SILVA, 2019, p. 5).

E, apesar das várias definições e compreensões existentes e explicitadas por diferentes pesquisadores:

\begin{abstract}
Registra-se, por fim, que não convém limitar a definição de websérie a uma única característica (necessidade de interação ou conteúdo exclusivo da internet, por exemplo), mas entendê-la como produto maleável, capaz de se construir com diferentes plataformas e propostas de intersecção. Inexistem regras fixas para produção de webséries; o que há são diretrizes, marcas que estão fortemente ligadas ao formato (a linguagem preferencialmente audiovisual, a serialização, a curta duração dos episódios, os enquadramentos fechados, a disponibilidade on-line, o investimento limitado, o público incerto), mas que não são exigências sacras. (HERGESEL, 2018, p. 143, grifo nosso).
\end{abstract}

Desse modo, visualiza-se que as webséries têm adquirido cada vez mais espaço no sistema midiático com diferentes finalidades: expandir e propor interação com o conteúdo da televisão; explorar novas ferramentas e públicos; produzir conteúdo com estilos diferenciados, que nem sempre são aceitos pela televisão. Ou seja, as mídias digitais têm propiciado a abertura para a experimentação e tentativas de novos modelos, narrativas, formatos, negócios e aproximação com a audiência juvenil.

Para Hergesel (2017, grifo nosso), o fenômeno das webséries pode partir de três modalidades de produção: dramaturgia, entretenimento e jornalismo. No caso das webséries selecionadas, o conteúdo - ainda que não seja objeto de análise deste estudo perpassa essas três esferas explicadas pelo autor. Entende-se, assim, que a websérie é uma narrativa audiovisual midiática, composta por uma serialização e pensada para as pequenas e móveis telas. Um cenário colaborado pela

[...] crescente utilização do computador, o avanço da internet (ainda que limitado em nosso país) e a aceleração do surgimento de novas ferramentas tecnológicas, o barateamento dos equipamentos e a facilidade ao acesso e manuseamento, demonstram o cenário em que a produção de conteúdo audiovisual - desenvolvido para a plataforma digital - se encontra. (SOUZA; CAJAZEIRA, 2016, p. 2).

Nesta perspectiva, as webséries em análise apresentam-se como pontos de partida e reflexão sobre as experiências e experimentações narrativas em áudio e vídeo na internet. Sobretudo neste atual momento, no qual o mundo tem vivenciado a necessidade do isolamento social, mas o que não significa deixar de produzir conteúdo. Como destaca Jorge Furtado, roteirista e escritor, em entrevista ao portal UOL (STYCER, 2020): tudo isso "é uma 


\section{Linguagens - Revista de Letras, Artes e Comunicação - ISSN 1981- 9943 \\ Blumenau, v. 14, n. 2, p. 181-195, maio/ago. 2020. \\ DOI: http://dx.doi.org/10.7867/1981-9943.2020v14n2p181-195}

aventura". O que propõe um olhar para a inovação, criatividade, desafios e oportunidades de produção audiovisual em consonância com a miniaturização das telas, o uso das redes telemáticas da internet e a inovação na produção audiovisual.

\section{A INOVAÇÃO DO PRODUTO AUDIOVISUAL EM TEMPOS DE CRISE}

Há quem diga que são em momentos de crise, de tempos tensos e instáveis que o ser humano se vale do "problema" para buscar novas soluções, mudanças e diferentes perspectivas que, possivelmente, não seriam identificadas tão facilmente em outros momentos. Ou, ao menos, não com tanto afinco e obstinação. A instabilidade e as crises, especialmente de cunho econômico, estabelecem condições para a busca pela inovação e a descoberta de novas possibilidades - a partir da experimentação. A esses tensionamentos atrela-se a chance de produzir, de conhecer e transformar os pensamentos e os modos de produção como no caso dos produtos audiovisuais com a websérie.

Essa inquietação, por assim dizer, além das necessidades cotidianas, funciona como a base para o surgimento do novo. Tal aspecto é vislumbrado, considerando o recorte desta comunicação, para refletir e compreender as mudanças ocasionadas na produção audiovisual. Contudo, não apenas no que se refere a questões estéticas ou econômicas, mas, também, como forma de continuar a produzir mesmo frente a tempos instáveis como no tempo presente.

É neste contexto de curiosidade, necessidade e possibilidade advindas com o desenvolvimento de novas tecnologias digitais, plataformas on-line, ferramentas tecnológicas na sociedade que propiciaram condições para o vislumbramento das webséries. Numa reflexão inicial agrega-se tais condicionamentos aos processos de inovação que, conforme relata Schumpeter (1982), compreende o setor econômico, industrial e capitalista. Para Castells (2001), a inovação somente ocorre quando há todo um conjunto a estar disponível ou uma movimentação a ser realizada. Assim, tem-se o desenvolvimento de novas linguagens e formatos, bem como plataformas e dispositivos de acesso, além, do trânsito de conteúdos no ciberespaço visto como um lugar aberto a explorações tecnológicas, mercadológicas e socioculturais.

Para Christofoletti (2018, p. 10, grifo nosso):

A inovação é, portanto, uma dimensão inconformada do fazer humano, que evita se acomodar ou cristalizar uma posição. A inovação envolve dinamismo, movimento, entusiasmo e doses generosas de deslumbramento. É insaciável, experimental, renovadora e revisionista. Futurista, efêmera e volúvel. Desapegada e indomável. 


\section{Linguagens - Revista de Letras, Artes e Comunicação - ISSN 1981- 9943 \\ Blumenau, v. 14, n. 2, p. 181-195, maio/ago. 2020. \\ DOI: http://dx.doi.org/10.7867/1981-9943.2020v14n2p181-195}

As características destacadas pelo autor direcionam para a reflexão desse momento atual, ainda incerto, ocasionado pela pandemia, pela necessidade de evitar o contato presencial para além dos muros domésticos (quando possível) e pela adoção de um projeto experimental para dar continuidade às atividades criativas, artísticas e audiovisuais. Uma movimentação que caminha conjuntamente com o crescimento exponencial das redes sociais digitais provenientes da internet, dos dispositivos móveis como os smartphones, diminuição das telas e a expansividade proporcionada pelas novas plataformas de produção e disponibilização como Vimeo, YouTube, Facebook, Instagram (gratuitos e abertos) e serviços de streaming (pagos, com a maioria dos conteúdos fechado para assinantes).

Nesse sentido, salienta-se as adaptabilidades das telas. Entre tamanhos e formatos da tela desde o cinema, passando pela televisão e adentrando o território das mídias móveis, ela nunca esteve tão presente na vida do homem como atualmente. Com isso, Serroy e Lipovetsky (2009, grifo nosso) compreendem a passagem da tela-espetáculo à telacomunicação, de uma tela para ao tudo-tela. Essa visão corrobora para explicitar desde o processo da miniaturização das telas a onipresença delas na sociedade.

\footnotetext{
Tela em todo lugar e a todo momento, nas lojas e nos aeroportos, nos restaurantes e bares, no metrô, nos carros e nos aviões. Tela de todas as dimensões, tela plana, tela cheia e minitela portátil; tela sobre nós, tela que carregamos conosco; tela para ver e fazer tudo. Tela de vídeo, tela em miniatura, tela gráfica, tela nômade, tela tátil; o século que começa é o da tela onipresente e multiforme, planetária e multimidiática (SERROY; LIPOVETSKY, 2009, p. 12).
}

Nesta perspectiva, as transformações da telas despertam para a criação e fruição de novos modos de produção e consumo, sobretudo o conteúdo audiovisual que, de acordo com Pavlik (2001), tem apresentado um dos aspectos mais interessantes dessa inovação e mudança com a mídia digital: as experimentações de novas formas narrativas, com elementos que constroem e compõem, não apenas o produto final, mas o próprio processo de produção cotidiano dos profissionais. Com isso, a construção narrativa é vista sob a produção de uma experiência social prefigurada no campo prático, textual e de recepção da estrutura da obra narrativa.

\section{EXPERIÊNCIAS E EXPERIMENTAÇÕES AUDIOVISUAIS NA INTERNET}

Para a observação e identificação dessas experiência narrativas em áudio e vídeo na internet, a presente investigação parte de quatro webséries produzidas durante a pandemia da covid-19 no primeiro semestre de 2020: Se Eu Estivesse Aí (Gshow); Alta Sociedade, Baixa 


\section{Linguagens - Revista de Letras, Artes e Comunicação - ISSN 1981- 9943 \\ Blumenau, v. 14, n. 2, p. 181-195, maio/ago. 2020. \\ DOI: http://dx.doi.org/10.7867/1981-9943.2020v14n2p181-195}

(Instagram); Sala de Roteiro (YouTube) e Diário de um Confinado (Globoplay). De propostas a plataformas distintas, cada uma dessas webséries acarreta num formato, num modo de utilizar as ferramentas, orçamentos disponíveis e a necessidade do distanciamento social desde a sua produção a disponibilização.

\subsection{SE EU ESTIVESSE AÍ (GSHOW)}

Contando com 10 episódios, o projeto audiovisual foi desenvolvido pelos atores Débora Falabella e Gustavo Vaz, em parceria com o Gshow - o site de entretenimento do Grupo Globo -, sendo produzida e exibida entre 10 de junho e 9 de julho de 2020. O projeto objetiva ser uma websérie imersiva, a partir dos recursos sonoros, na qual o espectador é instruído com alguns direcionamentos para uma melhor experiência. A websérie é narrada em primeira pessoa e a trama conta a história de um casal recém-separado, que durante a pandemia tenta resolver o fim da relação à distância, se valendo do uso das tecnologias.

A disponibilização da série ocorre semanalmente e pode ser acompanhada tanto pelo site do Gshow ou no perfil da websérie no Instagram sob o uso do IGTV, como plataforma de distribuição on-line. A experiência narrativa proporcionada por essa websérie busca inserir o espectador/usuário dentro da história e para isso se utiliza do áudio 3D (destacando a necessidade, para uma melhor experiência, do uso de fone de ouvido e da manutenção dos olhos fechados pelo sujeito). Ao mesmo tempo, é possível acompanhar a história pelo vídeos produzidos, proporcionando uma nova experiência auditiva e visual.

Em entrevista ao portal Gshow (2020), os atores e criadores da websérie, casal na vida real, que estão passando a quarentena juntos, explicaram que o objetivo da produção era desenvolver um formato diferente, em que o público pudesse vivenciar, em primeira pessoa, a história desse casal com duração por episódio de até 5 minutos. Da criação à edição, os atores fizeram um pouco de tudo, dentro de casa, contando com a colaboração remota e on-line de alguns profissionais e técnicos, para aprimorar a construção e experiência narrativa.

A análise dessa websérie direciona o olhar do pesquisador para a visualização de novas formas de montagem e construção da produção audiovisual. Num primeiro momento, desloca-se a compreensão desde a pré até a pós-produção, que são realizadas pelos atores. Não que esse fato seja uma novidade em si, o que não se figura como tal. Mas, há um entendimento de que se tem um movimento diferenciado de experimentação durante esse período no qual, a partir de um único local (a casa, por exemplo), todo o material é produzido remotamente, utilizando os recursos digitais disponíveis. 


\section{Linguagens - Revista de Letras, Artes e Comunicação - ISSN 1981- 9943 \\ Blumenau, v. 14, n. 2, p. 181-195, maio/ago. 2020. \\ DOI: http://dx.doi.org/10.7867/1981-9943.2020v14n2p181-195}

No caso da websérie Se Eu Estivesse Aí, os atores optaram por utilizar o áudio em 3D e elaborar uma nova experiência para o espectador/usuário da internet e, sobretudo, que se encontra no Instagram. Essas novas experimentações audiovisuais já apresentam propostas no campo jornalístico nacional e principalmente internacional, porém para o entretenimento brasileiro é uma linguagem experimental. Contudo, devido à atual situação de paralização das atividades de produção audiovisual ficcional de empresas, como a Rede Globo de Televisão, essas novas possibilidades de criação, utilização dos recursos e uso das plataformas on-line possibilitam e instigam a criação de novos formatos, como é o caso desta websérie.

Portanto, a rede social Instagram, enquanto plataforma de disseminação gratuita e acessível, dialoga com um público diferentemente daquele já conhecido pela televisão, bem como a estrutura e condições propostas pela web. Dessa forma, a própria duração da websérie, como já destacado no referencial, é modificada, possuindo duração menor, com baixo custo de orçamento e narrativa em áudio e vídeo desenvolvida para as pequenas e portáteis telas. E, assim, investindo em novas experiências tanto para quem produz, como para quem consome o produto audiovisual. Ou seja, vislumbra-se neste cenário estéticas diferenciadas, propostas narrativas ousadas e aproximação com o público do universo digital.

Além disso, compreende-se, por exemplo, que a proposta idealizada por essa websérie dificilmente seria um produto elaborado pela e para a televisão devido as suas características. A websérie do Gshow é um produto fruto não apenas da internet e de suas funcionalidades, mas do atual momento que requer caracteres inovadores, soluções práticas e viáveis para manter essa aproximação entre meio e público, uma relação mediada pelas tecnologias digitais.

\subsection{ALTA SOCIEDADE, BAIXA (INSTAGRAM)}

A segunda websérie analisada é a produção Alta Sociedade, Baixa desenvolvida por produtores independentes e tendo como plataforma de distribuição o Instagram. Escrita por Rodrigo Pitta e Marcello Bosschar, a "instasérie de quarentena", como é denominada pelos autores, é um dos primeiros formatos de websérie que dialogam com os cuidados sanitários e isolamento social. Os seus 8 episódios foram produzidos e disponibilizados entre 1 de maio e 23 de junho de 2020 na rede social.

Acerca do seu conteúdo, a websérie dialoga com o atual momento da pandemia e da quarentena do novo coronavírus ao fazer uma crítica social a essa alta sociedade que, mesmo diante das recomendações, continua a realizar festas e reuniões com aglomeração em suas 


\section{Linguagens - Revista de Letras, Artes e Comunicação - ISSN 1981- 9943 \\ Blumenau, v. 14, n. 2, p. 181-195, maio/ago. 2020. \\ DOI: http://dx.doi.org/10.7867/1981-9943.2020v14n2p181-195}

casas - uma realidade que vem sendo noticiada, sobretudo por sites especializados em celebridades. Assim, o casal Lídia e Arnoldo Coutinho (representando os anfitriões) decidem organizar uma festa e convidam os seus amigos para participar em seu apartamento. Além disso, a série aponta para outra realidade: a presença das domésticas nos lares durante a pandemia - outra situação que também vem sendo visibilizada pela grande mídia.

Mas, o que essa produção traz de inovador? Pode-se inferir que é a sua forma de produção, pois a sua gravação ocorre de modo remoto e individual e sob o auxílio de equipamentos caseiros como os smartphones. Cada ator ou atriz grava as suas cenas de suas próprias casas com seus próprios equipamentos, sob a supervisão da direção e dos figurinistas e, num segundo momento, a equipe de montagem e direção faz o processo de unificação dos arquivos gravados. Esse processo difere do modo já conhecido e vigente na produção audiovisual, visto que a interação face a face é uma característica desse modo de produção e da própria qualidade do material que vem sendo melhorado ano após ano.

Dessa forma, os efeitos de montagem e direção se apresentam com maior ênfase para que o resultado final apresente essa tessitura e essa interação, criando uma sensação no espectador de que os personagens estão no mesmo ambiente, especificamente num dado momento: na festa realizada na casa dos personagens principais da websérie (Lídia e Arnaldo Coutinho). É possível perceber que cada ator/personagem, representando um casal, grava num cenário diferente se utilizando para tal finalidade da apropriação de um cômodo como, por exemplo: o quarto, banheiro/closet (casal 1); sala e banheiro (casal 2) e quarto e sala (casal 3).

O trabalho do cenógrafo, neste caso, é tentar criar uma linha harmônica para a produção. Ou seja, detalhes como portas, cortinas ajudam nessa composição, bem como ângulos mais fechados e focados nos rostos dos personagens. Assim, a dinâmica de interpretação e captação das imagens realiza a função no que se refere à conexão entre os personagens, ainda que estejam em lugares e ambientes diversos. Nesta perspectiva, entendese que o formato desta websérie perpassa as características do meio digital e da produção de baixo orçamento, pensada e distribuída na e para internet.

\subsection{SALA DE ROTEIRO (YOUTUBE)}

Dentre as webséries analisadas, a websérie Sala de Roteiro possui um formato e estrutura mais simples. Criada pelo escritor e roteirista Antonio Prata e dirigida por Fernando Meirelles, essa produção audiovisual desenvolvida a partir do início de julho de 2020, em plena pandemia, está disponível na plataforma YouTube com dois episódios. O projeto se 


\section{Linguagens - Revista de Letras, Artes e Comunicação - ISSN 1981- 9943 \\ Blumenau, v. 14, n. 2, p. 181-195, maio/ago. 2020. \\ DOI: http://dx.doi.org/10.7867/1981-9943.2020v14n2p181-195}

apropria dos acontecimentos políticos brasileiros durante o período pandêmico, eventos reais, e os insere como se fossem elementos ou ideias fictícias para a construção de uma série de televisão. O grupo de roteiristas é formado pelos atores Andréa Beltrão, Mariana Lima, Enrique Díaz, Marcos Palmeira e William Costa, que se reúnem a partir de uma videoconferência para a definição dos rumos da série/temporada.

A estrutura da série utiliza como locação as próprias casas e lares dos atores e a interação entre os personagens se dá no espaço da videoconferência. Desse modo, o espectador tem a visão dos pequenos "quadrados" por onde cada personagem aparece na videochamada. Assim, ora se tem a visão global da tela, ora a narrativa foca em apenas um personagem, um quadrado, no qual é possível se ater aos detalhes dos cenários.

A duração dos episódios também segue a premissa básica e geral que vem sendo utilizada, com cerca de 10 minutos de duração. Além disso, a websérie Sala de Roteiro, ao utilizar a plataforma YouTube como canal de disponibilização, aproxima-se de diversos públicos e espectadores que utilizam cotidianamente essa plataforma popular de vídeo - e, o que demonstra a iniciativa pessoal, sem apoio financeiro, para o desenvolvimento do projeto. Identifica-se, assim, que o foco desta produção e narrativa audiovisual é menos a forma e mais o conteúdo. Ainda que não seja o objetivo da análise, é importante destacar a incredulidade dos acontecimentos políticos reais, que na websérie são apresentados como possibilidades narrativas e que são colocados em dúvida sobre "uma possível veracidade" e “credibilidade do por parte do espectador" da série.

Nesta perspectiva, Antonio Prata e Fernando Meirelles colocam em questão a reflexão sobre o estado atual da política brasileira que mais parece, aos olhos da ficção, uma grande piada e uma história inverossímil até mesmo para uma série ficcional. Contudo, a construção narrativa, com ferramentas digitais e a utilização de recursos que se aproximam do amador, acarreta na visualização dessa experiência e experimentação audiovisual, que demonstra a força e a vontade da realização audiovisual na internet mesmo frente aos desafios da realidade cotidiana.

\subsection{DIÁRIO DE UM CONFINADO (GLOBOPLAY)}

Dentre as webséries analisadas neste artigo, Diário de um Confinado apresenta uma estética e um resultado final mais elaborados, uma vez que a sua produção - ainda que seja realizada no ambiente doméstico - apresenta uma qualidade mais sofisticada em comparação com as webséries anteriormente descritas. A razão para tal feito é simples: Diário de um 


\section{Linguagens - Revista de Letras, Artes e Comunicação - ISSN 1981- 9943 \\ Blumenau, v. 14, n. 2, p. 181-195, maio/ago. 2020. \\ DOI: http://dx.doi.org/10.7867/1981-9943.2020v14n2p181-195}

Confinado foi elaborado como um produto híbrido: internet e televisão, disponibilizada no serviço de streaming Globoplay (Globoplay) e, posteriormente, aos sábados na Rede Globo de Televisão, além dos canais Multishow e GNT - empresas que pertencem ao Grupo Globo.

A websérie foi idealizada pelo ator e roteirista Bruno Mazzeo e pela diretora Joana Jabace, casados na vida real e passando o período da quarentena junto de seus dois filhos em seu apartamento no Rio de Janeiro. A série teve como locação o apartamento do casal e narra a história de Murilo, um jovem solteiro com mais de 30 anos que passa a quarentena sozinho e enfrenta as dificuldades durante esse período de isolamento da covid-19.

Por ser um projeto, primeiramente, idealizado para a internet e para o aplicativo Globoplay, a websérie apresenta os elementos basilares já identificados nos outros projetos como duração menor, também cerca de 10 minutos, poucos episódios, totalizando 12, e a distribuição dos episódios divididos em dois momentos: na primeira semana foram disponibilizados os 6 primeiros e a semana seguinte os outros 6 episódios.

Lançada em 26 de junho de 2020, a websérie Diário de um Confinado apresenta essa estética mais profissional, uma vez que recursos e equipamentos de última geração foram utilizados, com o auxílio das empresas do Grupo Globo, mas também apresenta peculiaridades que fizeram com que a websérie fizesse uso da gravação a partir do contato presencial entre os atores/personagens.

Dentre essas peculiaridades está o fato de os atores Bruno Mazzeo, Débora Bloch e Matheus Nachtergaele morarem no mesmo prédio, possibilitando o contato presencial para a gravação (que ocorreu no hall onde Bruno e Débora moram e na rua, num encontro entre Bruno e Matheus). Já com os outros atores e atrizes/personagens, o recurso de videoconferência também foi utilizado por esta produção audiovisual. Ademais, ao ser desenvolvida, inicialmente, para o Globoplay, a websérie restringe o seu acesso, pois é necessário ter uma assinatura mensal para acompanhar a maioria dos produtos exclusivos da plataforma de streaming - que somente depois foi lançado na TV aberta.

O que podemos concluir sobre tais produtos e experimentações audiovisuais, as quais é possível denominar de "crias da pandemia", é que, seja com poucos ou muitos recursos é possível propor novas formas e formatos audiovisuais na contemporaneidade. A utilização massiva das tecnologias digitais, especialmente durante esse período da história da humanidade, demonstra que o campo do audiovisual e das mídias digitais está em pleno desenvolvimento, em descoberta das possibilidades estéticas e narrativas. Assim, é em momentos como este que roteiristas, autores, atores e atrizes e grupos midiáticos ou 


\section{Linguagens - Revista de Letras, Artes e Comunicação - ISSN 1981- 9943 \\ Blumenau, v. 14, n. 2, p. 181-195, maio/ago. 2020. \\ DOI: http://dx.doi.org/10.7867/1981-9943.2020v14n2p181-195}

produtores independentes lançam no mercado novas possibilidades criativas, modelos de negócios e aproximam criador, criatura e público.

\section{CONSIDERAÇÕES FINAIS}

Ao visualizar as produções desenvolvidas pelas plataformas Gshow, Instagram YouTube e Globoplay, é possível afirmar que se apresentam frente ao caráter inovador, além do diálogo e interação com os espectadores/usuários nesse ecossistema midiático digital características advindas das transformações não somente tecnológicas, mas socioculturais, de novas rotinas produtivas e da manutenção das relações no contexto atual. Deste modo, essas experiências e experimentações audiovisuais possibilitam a reflexão e compreensão do próprio desenvolvimento de formatos audiovisuais, independente da pandemia ou de outros entraves que possam ocorrer futuramente.

Além de novos modelos de negócios, essas webséries potencializam (com ênfase na Alta Sociedade, Baixa e Sala de Roteiro) a utilização de equipamento de gravação e produção com baixo custo: câmeras de aparelhos celulares, plataformas de videoconferência e aplicativos para a gravação e captação das telas. A ubiquidade e produção multiplataforma se apresenta na websérie Diário de um Confinado, que ao ter uma estética e equipamentos de produção de maior qualidade parte do ambiente da internet para as telas da TV.

Não se trata necessariamente de ferramentas, plataformas e serviços inéditos, que somente no aqui e agora foram descobertos. Contudo, se trata de um processo de (re)descobrimento, (re)utilização desse entorno digital disponível para outros afazeres que foram realocados para a produção audiovisual ficcional na internet. Ou seja, em tempos de restrição há um aguçamento pela criação, pela produção com o que se tem próximo, cujo recurso e material pode ser facilmente acessado e executado.

Neste cenário de experimentações e transformações no fazer audiovisual para e na internet, visualiza-se outras produções e formatos que estão sendo desenvolvidos remotamente como: Sinta-se em Casa, Cada um no seu Quadrado, Sterblitch não tem talkshow: o talk show, Que tal um pouco de esperança e boas notícias? no Globoplay e; a mininovela produzida no perfil do Instagram do ator Pedroca Monteiro, narrando a história Ivanildo, o ex-marido e Letícia, a mãe de gêmeos, utilizando os recursos de filtros da rede social. São produtos que estão demonstrando as possibilidades e as versatilidades do conteúdo audiovisual em plataformas digitais. 


\section{Linguagens - Revista de Letras, Artes e Comunicação - ISSN 1981- 9943 \\ Blumenau, v. 14, n. 2, p. 181-195, maio/ago. 2020. \\ DOI: http://dx.doi.org/10.7867/1981-9943.2020v14n2p181-195}

Nesta perspectiva, a realização deste estudo propiciou a apresentação do atual momento de produção audiovisual a partir das webséries observando as características dessas quatro produções na internet e na interação através dessas plataformas com o público. O que se pode ressaltar é que elas destacam diferentes experiências não somente para quem as produz, mas para o público seja através do áudio em $3 \mathrm{~d}$, da visualização da interação entre os personagens a partir do processo de edição e/ou de identificar que as mídias digitais e audiovisuais ainda estão em fase de descobrimento pela sociedade.

\section{REFERÊNCIAS}

BARCELLOS, Nayara Cristinne Pinto. "Ester": uma websérie experimental para o Instagram. 2017. 88 f. Trabalho de Conclusão de Curso (Graduação em Comunicação Organizacional) - Universidade de Brasília, Faculdade de Comunicação, Brasília, 2017.

BARDIN, Laurence. Análise de conteúdo. Tradução de Luís Antero Reto e Augusto Pinheiro. São Paulo: 70, 2016.

BARTHES, Roland. Introdução à análise estrutural da narrativa. In: BARTHES, Roland et al. Análise estrutural da narrativa. Rio de Janeiro: Vozes, 1971.

CASTELLS, Manuel. La Galáxia Internet: reflexiones sobre internet, empresa y sociedad. Barcelona: Plaza \& Janés, 2001.

CHRISTOFOLETTI, Rogério. Prefácio. In: BRASIL, Antonio. (org.). Inovação no futuro do jornalismo: ensino e prática do noticiário do amanhã. Florianópolis: Insular, 2018.

GSHOW. 'Se eu estivesse aí': websérie com Débora Falabella e Gustavo Vaz tem formato inédito com áudio 3d. Gshow. 6 jun. 2020. Disponível em: https://gshow.globo.com/series/seeu-estivesse-ai/noticia/se-eu-estivesse-ai-webserie-com-debora-falabella-e-gustavo-vaz-temformato-inedito-com-audio-3d.ghtml. Acesso em: 11 jul. 2020.

HERGESEL, João Paulo. A websérie: um mapeamento bibliográfico acerca desse formato narrativo. Mediação, Belo Horizonte, v. 20, n. 27, jul./dez. de 2018.

HERGESEL, João Paulo; PICHIGUELLI, Isabella; SILVA, Míriam Cristina Carlos Midiatização da religião na ficção seriada infantojuvenil: narrativa e estilo na websérie -10 | A vida não é um jogo (Feliz Play). In: CONGRESSO BRASILEIRO DE CIÊNCIAS DA COMUNICAÇÃO, 42., 2019. Anais [...], Belém, 2019. Disponível em: https://portalintercom.org.br/anais/nacional2019/resumos/R14-0367-5.pdf. Acesso em: 20 jul. 2020.

HERGESEL, João Paulo. YouTube, Vimeo, Gshow, Netflix, Globo Play e o estilo da websérie de ficção no Brasil. In: CONGRESSO BRASILEIRO DE CIÊNCIAS DA COMUNICAÇÃO, 40., 2017. Anais [...], Curitiba, 2017. Disponível em: 


\section{Linguagens - Revista de Letras, Artes e Comunicação - ISSN 1981- 9943 \\ Blumenau, v. 14, n. 2, p. 181-195, maio/ago. 2020. \\ DOI: http://dx.doi.org/10.7867/1981-9943.2020v14n2p181-195}

https://portalintercom.org.br/anais/nacional2017/resumos/R12-1087-1.pdf. Acesso em: 20 jul. 2020.

MACHADO, Arlindo. A televisão levada a sério. São Paulo: Senac, 2000.

PAVLIK, J. Journalism and new media. New York: Columbia University, 2001.

SCHUMPETER, Joseph. A teoria do desenvolvimento económico: uma investigação sobre lucros, capital, crédito, juro e o ciclo económico. 3. ed., São Paulo: Abril Cultural, 1982.

SERROY, Jean; LIPOVETSKY, Gilles. A tela global: mídias culturais e cinema na era hipermoderna. Trad. de Paulo Neves. Porto alegre: Sulina, 2009.

SILVA, Marcel V. B. Cultura das séries: forma, contexto e consumo de ficção seriada na contemporaneidade. Galáxia, São Paulo, n. 27, p. 241-252, jun. 2014.

SILVA, Míriam Cristina Carlos; SANTOS, Tarcyanie Cajueiro. Peregrinação, experiência e sentidos: uma leitura de narrativas sobre o Caminho de Santiago de Compostela. E-Compós, Brasília, v. 18, n. 2, p. 1-15, maio/ago. 2015.

SOUZA, José Jullian. Explorando o conceito de websérie documental: lacunas, características e definição. Revista Eikon, Covilhã, v. 1, n. 7, 2020.

SOUZA, José Jullian Gomes de; CAJAZEIRA; Paulo Eduardo Silva Lins. Webdocumentário: a composição narrativa em bases de dados e a interatividade entre o produto audiovisual e o usuário. In: Congresso de Ciências da Comunicação na Região Sudeste, 21., 2016. Anais [...], Salto, 2016. Disponível em:

https://www.portalintercom.org.br/anais/sudeste2016/resumos/R53-0443-1.pdf. Acesso em: 20 jul. 2020.

STYCER, Mauricio. Globo usa casais da vida real para gravar série sobre amores na pandemia. 20 jul. 2020. Disponível em: https://tvefamosos.uol.com.br/colunas/mauriciostycer/2020/07/20/globo-usa-casais-na-vida-real-para-gravar-serie-sobre-amores-napandemia.htm. Acesso em: 20 jul. 2020.

WELLER, Daniel. O ciberdrama: roteiro na cibernética. In: COMPARATO, Doc. Da criação ao roteiro: edição revisada e atualizada com exercícios práticos. 5. ed. Rio de Janeiro: Rocco, 2000. p. 434-450.

ZANETTI, Daniela. Repetição, serialização, narrativa popular e melodrama. MATRIZes, São Paulo, ano 2, n. 2, p. 181-194, 2009. Disponível em:

http://www.revistas.usp.br/matrizes/article/viewFile/38230/41004. Acesso em: 20 jul. 2020. 